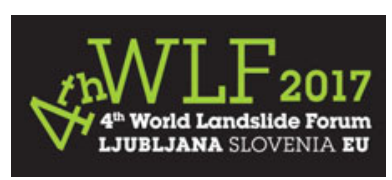

\title{
International Union of Geodesy and Geophysics (IUGG)_-Integrating Natural Hazard Science with Disaster Risk Reduction Policy
}

\author{
Alik Ismail-Zadeh
}

\begin{abstract}
Science-driven approaches to disaster risk reduction and management can help communities and governments become more resilient and reduce the human and economic impacts of disasters. The International Union of Geodesy and Geophysics (IUGG) promotes international scientific research and cooperation in natural hazards and disaster risks, and contributes to development of sound scientific knowledge on hazards, based on monitoring of physical phenomena and integrated observations, analysis, and modeling. IUGG makes scientific information available to people, and bridges advanced science with policymaking via international and intergovernmental programs. This report describes the union's major activities in the area of hazard and risk research and considers potential contribution of IUGG to the Sendai Partnerships. The contribution could include assessments of landslide hazards and risks; development of a scientific background to high-precision early warning systems for landslides; geophysical and geodetic monitoring of landslides; analysis and modeling of landslides and other rapid land movements; and relevant science education and capacity building.
\end{abstract}

\author{
Keyword \\ Geohazards • Risk assessment • International cooperation • IUGG
}

\section{Introduction}

Disasters triggered by geophysical events (e.g. landslides, earthquakes, volcanoes, tsunamis) continue to grow in number and impact. In many regions, geohazards are becoming direct threats to national security because their impacts are amplified by rapid growth of population, and unsustainable development practices, both of which increase exposure and vulnerabilities of communities, capital, and environmental assets. Reducing disaster risk using scientific

A. Ismail-Zadeh $(\bowtie)$

Institute of Earthquake Prediction Theory and Mathematical

Geophysics, Russian Academy of Sciences, Profsoyuznaya Str.

84/32, Moscow 117997 Moscow, Russia

e-mail: Alik.Ismail-Zadeh@kit.edu

A. Ismail-Zadeh

Institute of Applied Geosciences, Karlsruhe Institute of

Technology, Adenauerring 20b, Karlsruhe, 76131, Germany knowledge is a foundation for sustainable development (Cutter et al. 2015). For example, risk caused by landslides is evolving and growing despite considerable progress in understanding of mechanisms triggering landslides (e.g. Sassa and Canuti 2009; Reichenbach and Günther 2014). Our knowledge of geohazards and their interaction with human systems is lacking in some important areas and is being challenged by the unforeseen or unknown repercussions of a rapidly changing and increasingly interdependent world - one transformed by technological change, globalization of economic systems, and political and economic instability. In such a tightly coupled world, a disaster not only affects the immediate area where it occurs, but also has cascading impacts that can affect other nations near and far. Co-designed and co-productive integrated research on disaster risk and science-based disaster risk assessments coupled with political decisions could significantly reduce disasters (Ismail-Zadeh 2017). 
Since 2005, the International Consortium on Landslides (ICL) has promoted a holistic approach to research and learning on integrated Earth system risk analysis and sustainable disaster management via its International Programme on Landslides (IPL). At the Third World Conference on Disaster Risk Reduction (WCDRR) held in Sendai, Japan, in 2015, the ICL and its IPL contributed further to disaster reduction activities proposing the Sendai Partnerships 2015-2025 for Global Promotion of Understanding and Reducing Landslide Disaster Risk. Several international and intergovernmental organizations, which signed the Sendai Partnerships, agreed to mobilize their efforts "to pursue prevention, to provide practical solutions, education, communication, and public outreach to reduce landslide disaster risk" (Sassa 2015).

One of the signatory Partners of the Sendai Partnerships is the International Union of Geodesy and Geophysics (IUGG). The primary motivation for signing the document was that the partnerships may allow, via international scientific cooperation and inter-governmental decision-making, the best scientific knowledge about landslide hazards and risks to be integrated and implemented into the practice to reduce the risks and possible losses.

This paper outlines IUGG's activities related to promotion of studies in natural hazards, extreme events, and risks. It also discusses potential contributions of geophysical sciences and geodesy in support of the Sendai Partnerships.

\section{Promoting Natural Hazard Research}

IUGG (http://www.iugg.org) is a non-profit, non-governmental, scientific organization established in 1919. The IUGG mission is to initiate, promote and coordinate, through international cooperation, studies of the Earth and its environment in space for the benefit of humanity. Those physical, chemical, and mathematical studies related to natural hazards include geodynamics, tectonics, seismology, the generation of magmas, volcanism and lava flows, the hydrology, oceanic waves, hazards associated with atmosphere, cryosphere, ionosphere, and magnetosphere; and climatic and environmental changes influencing the frequency and severity of extreme events. IUGG is a vibrant modern scientific union of nations and individual scientists from all over the world promoting research, science education, and capacity building, and linking scientific knowledge to societal needs (Ismail-Zadeh and Beer 2009).

IUGG is composed of eight international, semi-autonomous, scientific associations promoting specific discipline(s) of geoscience: the International Association of Geodesy (IAG, maintaining observational services to monitor hazards and assist in disaster management), the International Association of Cryospheric Sciences (IACS, promoting research in snow avalanches and other types of cryospheric hazards and risks), the International Association of Geomagnetism and Aeronomy (IAGA, in extreme space weather), the International Association of Hydrological Sciences (IAHS, in flooding, severe precipitation, droughts and other hydrological hazards and risks), the International Association of Meteorology and Atmospheric Sciences (IAMAS, in hurricanes, storms, tornadoes, and other meteorological hazards and risks), the International Association for the Physical Sciences of the Oceans (IAPSO, in tsunamis) together with the International Association of Seismology and Physics of the Earth Interior (IASPEI, in surface ruptures, soil properties, earthquakes, and seismic hazard and risk assessment) and with the International Association of Volcanology and Chemistry of the Earth's Interior (IAVCEI, in volcano eruptions, lava, debris, lahar flows, landslides, and associated hazard and risk assessment). IUGG and its Associations operate through more than 110 scientific divisions, commissions, committees, working groups, and services. IUGG holds general and scientific assemblies, during which policies governing the union are discussed and adopted, and research programs requiring international participation are formulated, coordinated, and planned. At the assemblies, national delegates of IUGG Member countries pass resolutions on important scientific and science policy issues, particularly related to natural hazards and reduction of risks (Ismail-Zadeh 2016).

IUGG Associations work to set global standards for research, such as the International Terrestrial Reference Frame (ITRF 2014), the Manual of Seismological Observatory Practice (Bormann 2012), and the Guidelines for Professional Interaction during Volcanic Crises (IAVCEI Subcommittee for Crisis Protocols 1999). In particular, the International Terrestrial Reference Frame provides a realization (i.e., a set of coordinates of some points located on the Earth's surface) to the International Terrestrial Reference System, a world spatial reference system co-rotating with the Earth in its diurnal motion in space. World navigation systems are referenced either to a specific ITRF realization or to their own coordinate systems, which are then referenced to an ITRF realization. Precise navigation assists in monitoring natural hazards, particularly movements of landslides, lavas, lahar, and debris flows. IUGG Associations oversee eighteen geodetic and geophysical services, particularly those related to monitoring natural hazards. For example, IAG established an observing system - the Global Geodetic Observing System - which works with IAG's international services to provide the geodetic infrastructure necessary for monitoring the Earth system including hazards and disasters and for global change research (Plag and Pearlman 2009). 


\section{Strengthening International Cooperation}

IUGG makes research visible to the international scientific community, to government agencies, to industry, and to the public in general through its education and outreach activities. Furthermore, science policy is an essential component of IUGG activities related to dissemination of scientific knowledge among the countries and the public (Ismail-Zadeh 2016).

IUGG has initiated and/or supported collaborative efforts that have led to highly productive worldwide interdisciplinary research and outreach programs related to natural hazards, disaster risks and sustainability. The International Hydrological Decade (1965-74), the Global Atmospheric Research Programme (1967-80), and the International Lithosphere Program (1980-present) have been promoting research in floods, hurricanes, earthquakes, volcanoes, and land movements and their hazard/risk assessments.

After the 2004 Indian Ocean earthquake and tsunami, IUGG scientists put forward an initiative about integrated studies on disaster risks, and convinced the International Council for Science (ICSU) to develop a major program on this topic to understand complicated natural and social processes and to contribute to disaster risk reduction. Since 2008, when the scientific program "Integrated Research on Disaster Risk" (IRDR) was established by ICSU and co-sponsored by the International Social Sciences Council (ISSC) and the U.N. Office for Disaster Risk Reduction, IUGG has been working closely with the IRDR Scientific Committee on the problems related to natural hazards and disaster risks (e.g. Ismail-Zadeh et al. 2014; Cutter et al. 2015).

IUGG has developed productive partnerships related to natural and human-induced hazards and disaster risk reduction with several intergovernmental organizations including the Group on Earth Observations, the International Civil Aviation Organization (ICAO), the Preparatory Commission for the Comprehensive Nuclear-Test-Ban Organization, U.N. Committee of Experts on Global Geospatial Information Management, U.N. Environment Programme, U.N. Education, Scientific and Cultural Organization (UNESCO), and the World Meteorological Organization (WMO). Particularly, IUGG has been cooperating for decades with the UNESCO International Hydrological Programme on topics related to hydrological hazards and risks, and with the Intergovernmental Oceanographic Commission on topics related to tsunami research and early warning systems. Since 1955, IUGG has been cooperating with WMO in meteorology, climate research, hydrology, cryosphere, space weather, volcanology, and related aspects of hazards and disaster risk analysis. For example, after the 2010 Eyjafjallajökull volcano eruption, and at a request of
ICAO, WMO and IUGG established the joint Volcanic Ash Scientific Advisory Group, which provides scientific advice on volcanic ash to civil aviation.

\section{Contributing to Disaster Risk Reduction}

IUGG promotes scientific knowledge related to disaster risk reduction. The most recent activities of the Union have been related to understanding extreme events, their societal implications, and scientific assessment of disaster risks (e.g. Ismail-Zadeh and Takeuchi 2007; Ismail-Zadeh et al. 2014; Ismail-Zadeh and Cutter 2015).

In 2009, IUGG initiated a major project "Extreme Natural Hazards and Societal Implications-ENHANS" supported by ICSU, international scientific unions, and several international and intergovernmental bodies (http://www.icsugeounions.org/enhans). The principal goals of the project were: to improve understanding of critical phenomena associated with extreme natural events; to analyze impacts of the natural hazards on sustainable development of society; to promote studies on the prediction of extreme events and on natural hazards mitigation; to disseminate scientific knowledge and data on natural hazards and disaster risks for the advancement of research and education in general and especially in developing countries; and to establish links and networks with the organizations involved in research on extreme natural hazards and their societal implications. The goals of the ENHANS project were achieved via scientific meetings and open forums that brought together research experts, decision makers, disaster managers, insurance agency practitioners, and mass-media representatives. The project placed special emphasis on the importance of research on extreme natural hazards and disaster risk mitigation in the most vulnerable regions of the world, particularly in Latin America and the Caribbean, Africa, Middle East, Asia and the Pacific. The project contributed to, and promoted, research activities in natural hazard and disaster risk reduction, in particular via implementation of the IRDR Programme.

The ENHANS Declaration called for the following actions: (i) to promote comprehensive holistic inter- and trans-disciplinary approaches to natural hazard and disaster risk research, which have to integrate knowledge from natural and social sciences, mathematics, engineering, disaster management, insurance sectors and other stakeholders dealing with disaster risk; (ii) to help in networking existing regional scientific and educational centers with the aim to establish a regional center of excellence in disaster risk research (e.g. in sub-Sahara Africa); and (iii) To negotiate on setting up a process of assessing and synthesizing the 
policy-relevant results of peer-reviewed published research on the understanding of the natural phenomena and the social vulnerability associated with disasters; on the capability of predictive systems to disseminate timely and accurate information needed for policy and decision making; on methodologies and approaches for reducing vulnerability and increasing resilience of societies; and on the overall ability of societies to reduce risk (prevent, mitigate and prepare for the increasing impact of natural events). The proposed assessments could contribute to enhancement of the knowledge on disaster risk at global, regional, and local levels, and to the awareness of the people living with risk. The scientific assessments would help policymakers to develop a policy for significant reduction of disasters (Ismail-Zadeh et al. 2014).

Following an IUGG intervention on the topic of disaster risk assessments at the 2011 ICSU General Assembly in Rome, Italy, an ad hoc group of scientific experts on disaster risk reduction was set up by ICSU, with an ISSC participation, to analyze the state of the art in disaster risk science and risk assessment and to prepare a synthesis report on the topic. The 2014 ICSU General Assembly in Auckland, New Zealand, urged its Members to work closely with international and intergovernmental bodies in order to integrate scientific knowledge on disaster risks and risk assessments into decision-making and actions, and invited ICSU National Members to actively encourage their governments to support the proposed intergovernmental disaster risk assessment process. The report called for a multidisciplinary unified risk assessment, and its summary for policymakers was distributed to representatives of national governments attending the WCDRR in Sendai in 2015 (Ismail-Zadeh and Cutter 2015).

\section{Supporting Landslide Disaster Risk Reduction}

A landslide is one of the major geological hazards, which may lead to a disaster in vulnerable areas. The areas of high landslide risk are inhabited by 66 million people occupying a land surface of about $820,000 \mathrm{~km}^{2}$ (Dilley et al. 2005). The social impact of landslide disasters is significant, and it may continue to increase in the future due to the expansion of human settlements in mountainous areas, urbanization processes, and landscape modifications (Alcántara-Ayala 2014).

Understanding physical processes associated with landslides, predicting their extreme behavior, forecasting magnitude, time and place of landslide events as well as assessing vulnerability and risk are challenging problems. Landslides can be triggered by earthquakes, soil liquefaction, rainfalls, and volcanic eruption; submarine landslides in the ocean floor can trigger tsunami waves. These concatenated events may impact vulnerable communities and lead to disasters. Moreover, climate change may intensify the risk of landslides through an increase in the frequency and magnitude of rainfall (IPCC 2012).

IUGG promotes scientific studies of rainfalls, earthquakes, volcanic eruptions, and tsunamis which are linked to landslide hazards (e.g. Babayev et al. 2010; Gudmundsson 2012; Kremer et al. 2012; Yin et al. 2015; Emberson et al. 2016). Also the union encourages analysis, modeling, and risk assessments related to natural hazards including landslides, lahars, lava, and debris flows, avalanches and rock falls (e.g. Crutchley et al. 2013; Edwards et al. 2014; Korotkii et al. 2016).

For example, Crutchley et al. (2013) developed a marine seismic dataset collected over volcanic landslide deposits, acquired offshore of the Soufrière Hills volcano on the island of Montserrat in the Lesser Antilles. These data allow for detailed quantitative analysis of mass movements and of their manifestations, such as surface deformation and the distribution of transported blocks. Three-dimensional time-dependent numerical models of mass movements (Fig. 1) can assist in realistic simulations of the natural processes (e.g. Ismail-Zadeh et al. 2001; Tsepelev et al. 2016).

Global Positioning System (GPS), Global Navigation Satellite System (GNSS), and radar interferometry (InSAR) became useful tools in monitoring surface dynamics, and in detecting change in the motion through measurement of surface displacement (e.g. Scaioni 2015). The IAG's GGOS (Fig. 2) and its geodetic services provide the highest quality GPS/GNSS and InSAR data in support of scientific research on landslides, monitoring of land instability, early warnings, rescue, and damage assessment (Dow et al. 2009).

IUGG's associations such as IAG, IAHS, IASPEI, and IAVCEI as well as the IUGG Tsunami and GeoRisk Commissions can contribute to the Sendai Partnerships. IUGG Associations work with relevant engineering communities (e.g. the U.S. Army Corps of Engineers, the European Association of Earthquake Engineering) to reduce physical vulnerability through proper land use and urban planning, building codes, risk assessments, and early warning systems, and with insurance companies to mitigate disasters associated with natural hazards. Also the union promotes trans-disciplinary education in disaster risks (Declaration 2015), and hence could contribute to relevant capacity building activities.

\section{Concluding Remarks}

Sound scientific knowledge based on integrated observations, analysis and modeling, and scientific information available to policymakers along with interpretations of the knowledge in ways that accommodate diverse and unique local needs and expectations are important components in 


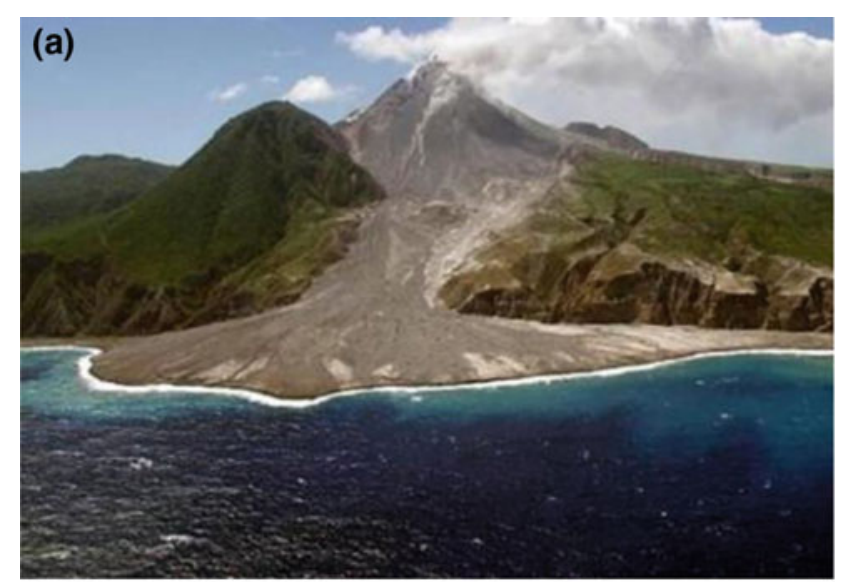

(b)
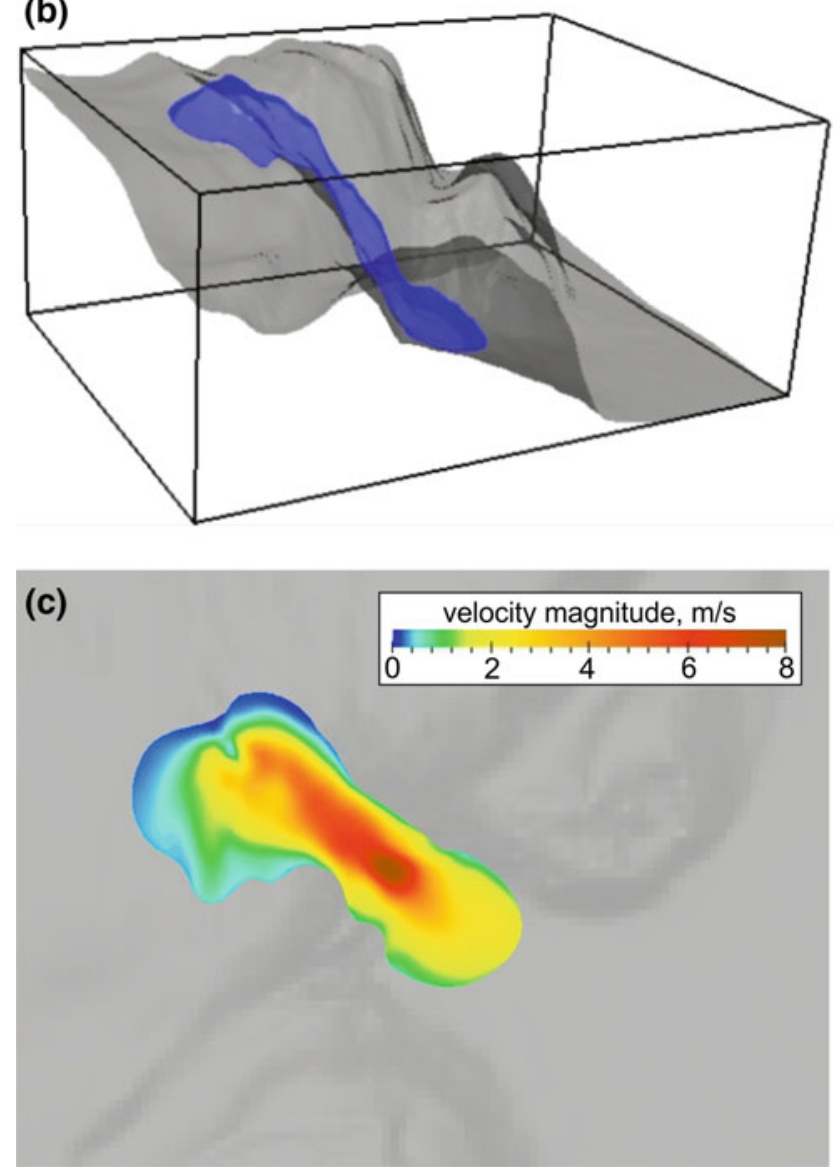

Fig. 1 Observed volcano landslide and modeled fluid flow. (a) An aerial view of the Soufriere Hills volcano on the island of Montserrat in the Lesser Antilles, which presents a volcanic dome collapse into the sea (Credit the National Oceanography Centre, Southampton, UK). (b) Snapshot of a modeled flow on a topographic surface and (c) the flow rates

managing future risks. IUGG bridges advanced science with policymaking via international and intergovernmental programs. Timely interventions and sustained efforts to support disaster risk management including scientific research,

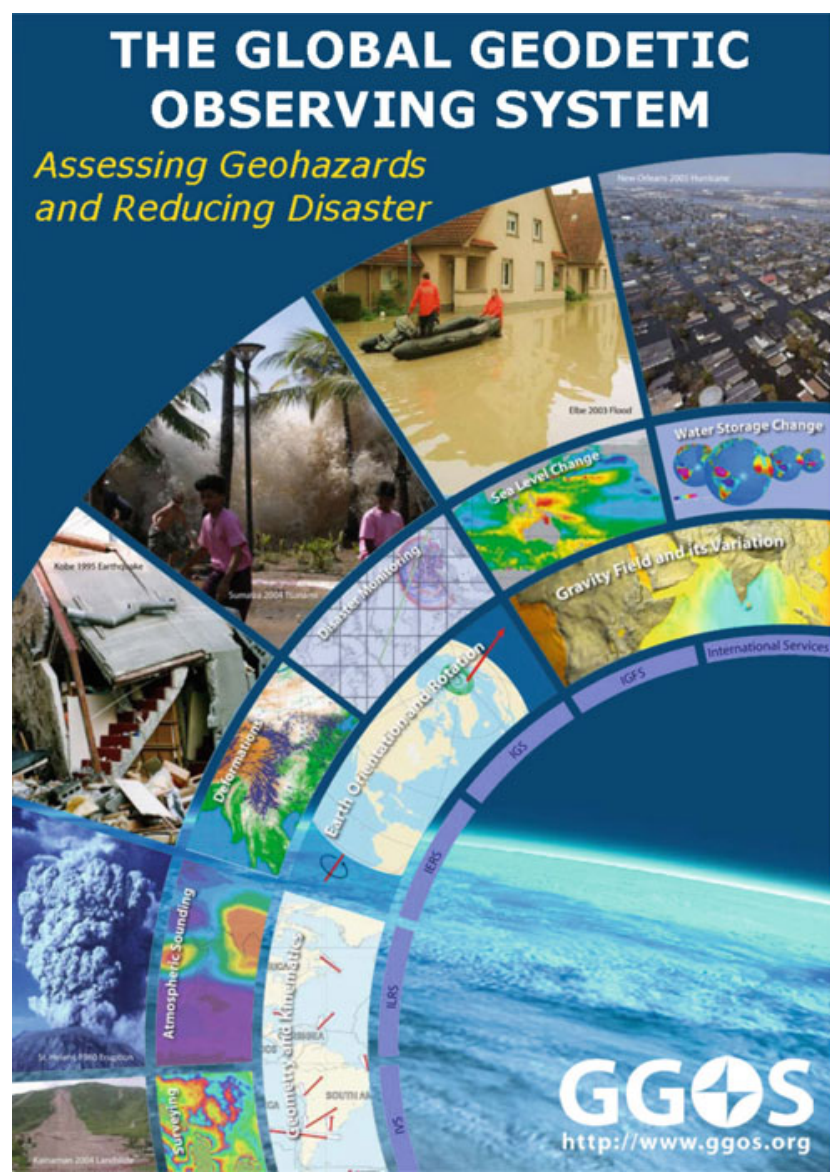

Fig. 2 Geodetic observations play a crucial role in assessment of natural hazards and disaster prevention/mitigation (image by IAG/GGOS)

management and resilience building can enhance sustainable development efforts.

A contribution of the IUGG to the Sendai Partnerships can include (but is not limited to) the following:

- scientific research related to understanding of landslide hazard and disaster risk;

- development of a scientific foundation for reliable prediction of landslides and for landslide early warning system of increased precision;

- landslide hazard and vulnerability assessments, and multi-hazard risk identification;

- improved technologies for monitoring, testing, and analysis of landslides and their analogue and computer simulations;

- teaching courses and tools on natural hazards.

Acknowledgements The author acknowledges the International Consortium on Landslides for its efforts in promoting research and capacity building and for its contribution to reduction of disasters 
caused by landslides. The research on lava-debris flow presented in Fig. 1 was supported by the Russian Science Foundation (grant 14-17-00520).

\section{References}

Alcántara-Ayala I (2014) The special-temporal dimensions of landslide disasters. In: Ismail-Zadeh A, Fucugauchi J, Kijko A et al (eds) Extreme natural events, disaster risks and societal implications. Cambridge Univ. Press, Cambridge, pp 113-125

Babayev G, Ismail-Zadeh A, Le Mouël J-L (2010) Scenario-based earthquake hazard and risk assessment for Baku (Azerbaijan). Nat Hazards Earth Sys Sci 10:2697-2712

Bormann P (ed) (2012) New manual of seismological observatory practice (NMSOP-2). IASPEI and GFZ German Research Centre for Geosciences, Potsdam, Germany

Crutchley GJ, Karstens J, Berndt C, Talling PJ, Watt SFL, Vardy ME, Hühnerbach V, Urlaub M, Sarkar S, Klaeschen D, Paulatto M, Le Friant A, Lebas E, Maeno F (2013) Insights into the emplacement dynamics of volcanic landslides from high-resolution 3D seismic data acquired offshore Montserrat, Lesser Antilles. Mar Geol 335:1-15

Cutter S, Ismail-Zadeh A, Alcántara-Ayala I, Altan O, Baker DN, Briceño S, Gupta H, Holloway A, Johnston D, McBean GA, Ogawa Y, Paton D, Porio E, Silbereisen RK, Takeuchi K, Valsecchi GB, Vogel C, Wu G (2015) Pool knowledge to stem losses from disasters. Nature 522:277-279

Declaration (2015) Future earth and space science education. Available at: http://www.icsu-geounions.org/files/FutureESSE_Declaration. pdf. Accessed on 25 Jul 2016

Dilley M, Chen RS, Deichmann W, Lerner-Lam AL, Arnold M (2005) Natural disaster hotspots: a global risk analysis. The World Bank, Washington D.C

Dow JM, Neilan RE, Rizos C (2009) The International GNSS Service in a changing landscape of Global Navigation Satellite Systems. J Geodesy 83:191-198

Edwards BR, Belousov A, Belousova M (2014) Propagation style controls lava-snow interactions. Nat Commun 5:5666. doi:10.1038/ ncomms6666

Emberson R, Hovius N, Galy A, Marc O (2016) Chemical weathering in active mountain belts controlled by stochastic bedrock landsliding. Nat Geosci 9:42-45

Gudmundsson A (2012) Strengths and strain energies of volcanic edifices: implications for eruptions, collapse calderas, and landslides. Nat Hazards Earth Syst Sci 12:2241-2258

IAVCEI Subcommittee for Crisis Protocols (1999) Professional conduct of scientists during volcanic crises. Bull Volcan 60:323-334
IPCC (2012) Summary for policymakers. In: Managing the risks of extreme events and disasters to advance climate change adaptation In: Field CB et al., Barros V, Stocker TF, Qin D, Dokken DJ, Ebi KL, Mastrandrea MD, Mach KJ, Plattner G-K, Allen SK, Tignor M, Midgley PM (eds) A special report of working groups I and II of the intergovernmental panel on climate change. Cambridge University Press, Cambridge, UK, and New York, NY, USA, pp 1-19

Ismail-Zadeh A, Beer T (2009) International cooperation in geophysics to benefit society. EOS 90(51):493, 501-502

Ismail-Zadeh A, Cutter S (eds) (2015) Disaster risks research and assessment to promote risk reduction and management. ICSU-ISSC, Paris, France

Ismail-Zadeh A (2016) Geoscience international: the role of scientific unions. Hist Geo Space Sci 7:103-123

Ismail-Zadeh A, Takeuchi K (2007) Preventive disaster management of extreme natural events. Nat Haz 42:459-467

Ismail-Zadeh A, Cutter SL, Takeuchi K, Paton D (2017) Forging a paradigm shift in disaster science. Nat Hazards 86:969-988

Ismail-Zadeh A, Urrutia Fucugauchi J, Kijko A, Takeuchi K, Zaliapin I (eds) (2014) Extreme natural hazards. Cambridge University Press, Cambridge, UK, Disaster Risks and Societal Implications

Ismail-Zadeh AT, Korotkii AI, Naimark BM, Tsepelev IA (2001) Numerical simulation of three-dimensional viscous flows with gravitational and thermal effects. Comput Mathem Math Phys 41:1331-1345

ITRF (2014) The international terrestrial reference frame, 2014 release. Available at: http://itrf.ensg.ign.fr/ITRF_solutions/2014. Accessed on 25 Jul 2016)

Korotkii A, Kovtunov D, Ismail-Zadeh A, Tsepelev I, Melnik O (2016) Quantitative reconstruction of thermal and dynamic characteristics of lava from surface thermal measurements. Geophys J Int 205:1767-1779

Kremer K, Simpson G, Girardclos S (2012) Giant Lake Geneva tsunami in AD 563. Nat Geosci 5:756-757

Plag H-P, Pearlman M (eds) (2009) Global geodetic observing system. Springer-Verlag, Berlin-Heidelberg

Reichenbach P, Günther A (2014) Progress in landslide hazard and risk evaluation. Nat Hazards Earth Syst Sci 14:2711-2713

Sassa K (2015) ISDR-ICL Sendai Partnerships 2015-2025 for global promotion of understanding and reducing landslide disaster risk. Landslides 12:631-640

Sassa K, Canuti P (eds) (2009) Landslides-disaster risk reduction. Springer-Verlag, Berlin-Heidelberg

Scaioni M (ed) (2015) Modern technologies for landslide monitoring and prediction. Springer, Heidelberg-New York-Dordrecht-London

Tsepelev I, Ismail-Zadeh A, Melnik O, Korotkii A (2016) Numerical modeling of fluid flow with rafts: an application to lava flows. J Geodyn 97:31-41

Yin Y, Li B, Wang W (2015) Dynamic analysis of the stabilized Wangjiayan landslide in the Wenchuan Ms 8.0 earthquake and aftershocks. Landslides 12:537-547
Open Access This chapter is licensed under the terms of the Creative Commons Attribution 4.0 International License (http://creativecommons. org/licenses/by/4.0/), which permits use, sharing, adaptation, distribution and reproduction in any medium or format, as long as you give appropriate credit to the original author(s) and the source, provide a link to the Creative Commons license and indicate if changes were made.
The images or other third party material in this chapter are included in the chapter's Creative Commons license, unless indicated otherwise in a credit line to the material. If material is not included in the chapter's Creative Commons license and your intended use is not permitted by statutory regulation or exceeds the permitted use, you will need to obtain permission directly from the copyright holder. 